\title{
Sore Throat, CTCAE
}

National Cancer Institute

\section{Source}

National Cancer Institute. Sore Throat, CT CAE. NCI Thesaurus. Code C143853.

A disorder characterized by marked discomfort in the throat 